\title{
Chimpanzee food preferences, associative learning, and the origins of cooking
}

\author{
Michael J. Beran ${ }^{1}$ • Lydia M. Hopper ${ }^{2}$ Frans B. M. de Waal ${ }^{3} \cdot$ Ken Sayers $^{1}$ • \\ Sarah F. Brosnan ${ }^{1}$
}

Published online: 10 December 2015

(C) Psychonomic Society, Inc. 2015

\begin{abstract}
A recent report suggested that chimpanzees demonstrate the cognitive capacities necessary to understand cooking (Warneken \& Rosati, 2015). We offer alternate explanations and mechanisms that could account for the behavioral responses of those chimpanzees, without invoking the understanding of cooking as a process. We discuss broader issues surrounding the use of chimpanzees in modeling hominid behavior and understanding aspects of human evolution.
\end{abstract}

Keywords Chimpanzees · Cooking $\cdot$ Evolution $\cdot$ Hominids · Associative Learning

In a recent study in which chimpanzees could exchange a raw slice of potato for a cooked one, Warneken and Rosati (2015) asserted that this process could be conceptualized as "cooking." Specifically, the authors concluded that the "chimpanzees thought that the cooking device transformed raw into cooked food." The study was developed to test whether chimpanzees have the cognitive capacities for cooking, in the context of the long-held hypothesis that cooked food was integral in human evolution (Darwin,

Contribution Statement: All authors contributed to writing this commentary.

Michael J. Beran

mjberan@yahoo.com

1 Department of Psychology and Language Research Center, Georgia State University, University Plaza, Atlanta, GA 30302, USA

2 Lincoln Park Zoo, Chicago, IL, USA

3 Emory University, Atlanta, GA, USA
1874/1998; Engels, 1876/1953; Wrangham, 2009). We find this hypothesis to be an interesting one, and are pleased to see relevant investigations consider the behavior of nonhuman primates. We strongly support the idea that one can approach complicated behavioral patterns and conceptual knowledge of such behaviors as cooking by studying constituent capacities that likely underlie those complicated behaviors. Such approaches, when done with multiple species, and ideally in conjunction with an assessment of developmental data from humans, advance our understanding of the emergence of the complicated cognitive and behavioral patterns shown by humans (and, perhaps, by hominid ancestors) by identifying these constituent capacities. Such capacities might be shared by many species (and be evident early in human development), or one might find such capacities lacking in other species, thereby highlighting uniquely human characteristics.

Cooking is one capacity that appears to be unique to humans, as we know of no demonstrations that another primate or nonprimate species naturally cooks its food. However, Warneken and Rosati (2015) suggested that chimpanzees likely could appreciate and understand how to do it. We remain agnostic as to this conclusion on the basis of the data they provided. Rather, we argue that Warneken and Rosati provided more information about chimpanzees' food preferences, and their willingness to exchange less-preferred for morepreferred foods, than about how chimpanzees might conceptualize cooking. These are aspects of chimpanzee behavior we already knew about, and although this does not mean that chimpanzees cannot understand cooking, we argue that a deeper consideration of basic preferences and learning mechanisms in apes could provide the same pattern of results without the need to infer any understanding of cooking. Beyond questioning the claim that chimpanzees understand cooking, we also consider whether there is a strong case to be made that they should. 


\section{Warneken and Rosati (2015)—Experiments and results}

Through a series of experiments, Warneken and Rosati (2015) showed that chimpanzees preferred cooked over uncooked potatoes (Exp. 1) and were willing to trade the less-preferred uncooked potatoes for the more-preferred cooked ones (Exps. 2 and 3). They also reported that the chimpanzees preferred a pot that they could use to exchange uncooked for cooked potato over one that did not produce cooked potato (Exps. 4 and 5). From this, the authors suggested that this indicated that the chimpanzees saw "cooking" as a process of transforming food. They also tested the chimpanzees' ability to generalize what they had learned about the cooking pots when presented with a new food (Exp. 6). The chimpanzees were given cooked potato, raw potato, or raw carrot (but not cooked carrot) that could either be consumed or placed in the cooker. The chimpanzees placed the raw foods into the cooker, but they tended to eat the cooked potato immediately. Finally, Warneken and Rosati tested whether chimpanzees would transport, and keep, raw food to be used in the "cooking pot" (Exps. 8 and 9). The chimpanzees appeared to do so, suggesting that they anticipated later putting those food items into the cooking device. ${ }^{1}$

\section{Is knowledge of cooking really required to explain the chimpanzees' responses?}

As chimpanzee researchers, we agree that the results from all nine experiments were to be expected, and would likely be replicated with other apes. More specifically, we agree that, on the whole, the results show that (1) chimpanzees preferred cooked over uncooked foods, (2) chimpanzees showed some self-control in not eating available uncooked foods when they could obtain cooked foods later, and (3) chimpanzees may have anticipated the later opportunity for cooked foods and adjusted their present behavior to make that later opportunity more likely. We agree with these conclusions because past research has already demonstrated these capacities in chimpanzees. However, we do not believe that the preferences and

\footnotetext{
${ }^{1}$ Some experiments in Warneken and Rosati (2015) presented methodological concerns. First, the experimenters presumably had an expectation that the chimpanzees might prefer one container over the other, and yet limited controls were in place to prevent the experimenter from cuing the chimpanzees (Beran, 2012). Second, their intertemporal choice test made use of pointing to food items as the measured response. It is difficult for nonhuman primates to inhibit pointing to larger or better amounts of visible food (e.g., Boysen \& Berntson, 1995), and this leads to an interpretive dilemma regarding claims that pointing to more or better food is reflective of self-control by animals, rather than reflecting difficulty with inhibiting this prepotent response (for more on this point, see Beran et al., 2014; Paglieri et al., 2013).
}

capacities shown in this series of experiments must indicate that the apes understand anything about the transformative process of cooking. Therefore, we discuss each of the three key findings in turn, relating them to previously reported data, and discuss alternative ways these capacities could be tested in more detail.

1. Preference for cooked over uncooked foods and willingness to trade for cooked food It has previously been shown that chimpanzees trade foods in their possession for foods they like better (Brosnan, Grady, Lambeth, Schapiro, \& Beran, 2008; Brosnan et al., 2007; Lefebvre, 1982; Lefebvre \& Hewitt, 1986), and like other animals, they also prefer cooked foods over raw ones (Bradshaw, Healey, Thorne, MacDonald, \& Arden-Clark, 2000; Ramirez, 1992; Wobber, Hare, \& Wrangham, 2008). We also know that chimpanzees (Hopper, Kurtycz, Ross, \& Bonnie, 2015) and capuchin monkeys (Evans \& Westergaard, 2006) will transport items to exchange for better items or, in the case of the monkeys, use them as tools to obtain higher-value foods. Thus, although it was shown that the chimpanzees preferred cooked to raw potato, which supports previous research, it was not additionally shown that they understood (or thought) that the cooked potato was a transformed version of the raw potato.

2. Preferences for the cooking pot over the noncooking pot and evidence for self-control Warneken and Rosati (2015) suggested that the preference for placing foods into the cooking pot suggested that chimpanzees understood that the cooking pot alone would transform uncooked into cooked foods. However, there is a much simpler explanation: Chimpanzees associated, through experience and learning, one container with the more-preferred cooked potato, and one with the less-preferred raw potato, and they chose the container associated with the morepreferred food. Again, as has been shown through decades of research using principles of associative learning, this is not surprising - many species learn associations between stimuli and food rewards of varying amounts, types, and values. And such learning does not require an interpretation of any knowledge about why a better food emerged. To give an example, if chimpanzees were given small slices of potato, and could return those slices to an experimenter to be buried and then to emerge as whole potatoes $1 \mathrm{~min}$ later, such exchanges need not invoke any understanding that the slices were "planted" and "grew" into new potatoes. But, we expect that chimpanzees would be as good at this task as the one with cooking pots, although we would not want to then claim knowledge of "farming" by chimpanzees.

By way of analogy, consider a microwave. The experience of seeing frozen foods that have been placed in a microwave become cooked foods does not require any 
understanding of that cooking process (as many parents of young children can attest - and in fact, most adults do not understand exactly how a microwave cooks food). Rather, the thing that people realize is that putting lowerpreference foods into a microwave leads to higherpreference foods coming out some time later, through the experiences of seeing that happen with repeated use of the microwave. We find it likely that this is what chimpanzees learned in Warneken and Rosati's (2015) studythat raw potato could be exchanged for cooked potato through the vessel provided by the experimenters - rather than learning anything about cooking as a process (i.e., that raw potato becomes cooked potato). To us, this seems quite similar to the example of the Koshima Island Japanese macaques learning to "season" their potatoes by dropping them in the salty ocean (de Waal, 2001; Hirata, Watanabe, \& Kawai, 2001). We know of no claims that the monkeys understand this process, almost certainly acquired when a macaque accidentally washed a potato in the ocean instead of the nearby freshwater stream and liked the results.

When given a new food (raw carrot), the chimpanzees placed this new food into the cooking pot. Again, this can be explained by preferences without claiming that chimpanzees were choosing to cook new raw foods. Rather, it seems that the chimpanzees ate things they liked (cooked potatoes) and got rid of those they did not like (raw potato and raw carrot) by utilizing the approach that had previous resulted in more-preferred foods (i.e., put them in the pot). What would have happened had the authors introduced a third container to the chimpanzees that always gave an uncooked, high-preference item? If the chimpanzees put their lower-preference foods into this pot, and ignored the cooker that supposedly made those items more preferred, it would be difficult to argue that the choices they made were to "cook" foods rather than merely to trade up to something better.

This trading behavior is well-established with chimpanzees in a variety of other self-control tests in which delayed rewards are obtained that are better than immediate ones (e.g., Beran, Rossettie, \& Parrish, 2015; Dufour, Pele, Sterck, \& Thierry, 2007). Furthermore, chimpanzees and other great apes will allow food quantities to continue to grow when delaying eating those items continues the accumulation (Beran 2002; Beran \& Evans, 2006; Evans \& Beran, 2007; Parrish et al., 2014; Stevens, Rosati, Heilbronner, \& Mühlhoff, 2011), a form of self-control that one might also infer is relevant to understanding cooking, in which the longer one waits (to a point), the better the food becomes.

Warneken and Rosati (2015) came closest to testing chimpanzees' understanding of cooking in Experiment 7, in which chimpanzees chose between a slice of potato and an inedible wood chip to put into the cooker, and they more often chose the potato slice. This may indicate that the chimpanzees associated the uncooked and cooked potatoes, and recognized that they needed to provide the "matching" food. However, it could also be explained by a preference for a known item (uncooked potato) over an unknown one (the wood chip), or a reflection of their preference for the uncooked potato over the wood chip (even if they preferred the cooked potato to both). Although this is not a conclusive test on its own, additional tests along these lines would help uncover what, exactly, the chimpanzees were basing their choices upon and whether there was any recognition of the possibility to transform food via cooking.

3. Delay of gratification and anticipation of later "cooking" opportunities It was shown that the chimpanzees would wait to trade raw foods, and even transport those foods rather than eat them. This is a compelling example of self-control, and perhaps of anticipatory behavior (e.g., Osvath \& Osvath, 2008; Raby \& Clayton, 2009). However, our interpretation of these results with regard to cooking knowledge follows from what we outlined above. Chimpanzees learned that not eating low-preference foods would allow them to exchange those for higher-preference foods, but such learning does not require understanding that a cooking process occurs. Here, additional testing could be conducted to distinguish whether or not knowledge of cooking was required. One could allow the chimpanzees to put items into the cooking device and also decide how long to cook the food. Warneken and Rosati (2015) always maintained control over the cooking pots, but if the chimpanzees were somehow given the pots, would they still choose to put food inside and wait for it to "cook"? What if taking it out too early meant that the food was only partly cooked, or if the food was spoiled by cooking it for too long? Could the chimpanzees learn to only leave the food in for an appropriate length of time, so as to avoid either (still) undercooked potato, or "burning" it? We suggest that some understanding of the temporal aspects of cooking would also be necessary to demonstrate before concluding that chimpanzees understand the process of cooking. Perhaps the chimpanzees would show these abilities, although they might not readily understand how time correlates with the degree of change in cooked foods. But even some sensitivity to the temporal aspects of cooking would support a claim that chimpanzees understand components of the cooking process. 


\section{Can chimpanzees understand cooking?}

Although we are playing the role of killjoys here (Shettleworth, 2010), this does not mean that chimpanzees cannot understand cooking, or that we think there is not something to be learned about the origins of human cooking from studying chimpanzees and other nonhuman animals. Rather, we argue that the data presented by Warneken and Rosati (2015) do not require such an interpretation. A key control condition that was lacking was to present chimpanzees with the choice of cooking and noncooking containers when the presented food was a type that would not be improved. For example, if it was shown that chimpanzees do not prefer cooked apples over raw apples, then they should not put apples in the cooking pot. One could present them with a frozen food that would melt and disappear when heated. Or, given that many primates seem to prefer to take hard items such as chow biscuits and soften them in water, would the chimpanzees understand that the cooking pot would make already-soft chow harder, and thus less palatable? If proficient choice of the correct container (cooking foods that get better with heat and not cooking foods that get worse) did not happen during generalization tests, and required the same degree of learning and experience with the introduction of each new food type as with previous types, then one likely should not argue that chimpanzees understood the concept of cooking. If, however, with some experience the animals came to generalize "better with cooking" and "worse with cooking" knowledge to new food types, this would strengthen the argument for some conceptual knowledge of what cooking is. A key point is that foods would have to be chosen that were of medium preference in a raw state, so that, for those that got better, the chimpanzees would want to cook them, but those that got worse would be acceptable to be eaten without cooking. Otherwise, a rule such as "eat what is good, put what is bad into the cooker" could explain choices without any need to understand that the cooking pot actually changes foods from one form to another.

\section{Should chimpanzees understand cooking?}

Warneken and Rosati's (2015) aim was to highlight the "domain-general cognitive capacities required for cooking," which, they proposed, are motivation, patience, inhibitory control, causal understanding, and planning. All are undoubtedly on the list of cognitive precursors to cooking, and as many years' worth of research has shown, chimpanzees have these capacities. However, showing that chimpanzees prefer cooked to uncooked potato, and will make choices to gain the more-preferred option, tells us very little about whether they understand the process of cooking. And, why should they? Unlike early hominids, chimpanzees lack fire or a diet heavy in foods whose nutritional value or palatability is increased through the act of cooking (they eat primarily fruit and leaves), so they lack both a mechanism for cooking and a motivation to develop it. Of course, at some point, so did early humans, and it is debatable whether a conception of cooking is even required initially. It is possible that a preference for cooked food, and the willingness to wait to acquire it, preceded such understanding.

Cooking has long been viewed as a pivotal hominid innovation. Darwin (1874/1998) and Engels (1876/1953) recognized the advantages of, in essence, partially "digesting" and/ or detoxifying foods before they entered the body. This is a uniquely human trait; how chimpanzees behave actually tells us more about what did not happen in the human lineage than about what did ("Jolly's paradox"; Jolly, 1970; Sayers \& Lovejoy, 2008), a point that Warneken and Rosati (2015) acknowledged. However, they suggested that their data shed light on (1) the abilities necessary for cooking that may have been shared with the last common ancestor of apes and humans and (2) how quickly cooking may have been adopted after the control of fire. Their data, unfortunately, contribute only marginally to these questions.

With respect to the first question, chimpanzees are not ideal surrogates for the Pan-Homo last common ancestor in terms of nonhomologous traits, as they are separated from this form by some 8 million years (Cachel, 2006; Latimer, White, Kimbel, Johanson, \& Lovejoy, 1981). For example, Ardipithecus ramidus, the oldest well-known hominid, at 4.4 million years ago, differs from chimpanzees in skeletal anatomy, including limb proportions and dentition, which in turn relate to ecology and social structure (Lovejoy, Suwa, Simpson, Matternes, \& White, 2009; Sayers \& Lovejoy, 2014; Sayers, Raghanti, \& Lovejoy, 2012; Suwa et al., 2009; White et al., 2009). The point here is that chimpanzees, bonobos, and their precursors have been evolving, and apparently substantially so, right along with (but separately from) our immediate ancestors.

It is true that chimpanzees show many of the cognitive precursors that may have been evolutionarily co-opted when humans began to cook, including tool manufacture and transport (Boesch \& Boesch, 1984; Sanz, Call, \& Morgan, 2009), planning (Ban, Boesch, \& Janmaat, 2014; Janmaat, Polansky, Ban, \& Boesch, 2014; Mulcahy \& Call, 2006), prospective memory (Beran, Perdue, Bramlett, Menzel, \& Evans, 2012), and self-control (e.g., Beran \& Evans, 2006; Dufour et al., 2007; Evans \& Beran, 2007). Perhaps these capacities, realized in chimpanzees and hominids in natural circumstances, were only co-opted by hominids when they learned to harness fire toward the new goal of gathering and transforming certain kinds of foods in ways that we now call cooking. But what if these capacities, in whole or in part, are also present in other primates, or mammals, or vertebrates that are much less closely related to humans? Convergent evolution and/or deep homology appear to have promoted many of these capacities in 
other species beyond apes. Motivation (Dashiell, 1925), inhibitory control (Reynolds, De Wit, \& Richards, 2002), causal understanding (Blaisdell, Sawa, Leising, \& Waldmann, 2006), and planning (Crystal, 2013), for example, have all been claimed, to various degrees, in rats. Vervet monkeys, like chimpanzees, exploit areas burned by wildfires for ranging and feeding purposes (Herzog et al., 2015; Herzog et al., 2014; Jaffe \& Isbell, 2009), and it is likely that a wide variety of captive animals, primate and nonprimate alike, would prefer cooked to uncooked foods, due to considerations from optimal foraging theory (Charnov, 1976; Schoener, 1971; Wrangham, 2009). Some of the purported psychological prerequisites for cooking may have been around a long time, perhaps tens of millions of years, something that cannot be recognized without applying a more broadly comparative approach (i.e., extending the discussion beyond chimpanzees or apes generally).

Other problems - including some concerning the second question, on the rapidity of hominid behavioral change-arise from a taxonomically limited focus. For example, Warneken and Rosati (2015) suggested that, in addition to the control of fire, a slight modification in diet and increased social tolerance (as compared to chimpanzees) could lead to regular hominid cooking. This is assuming, again, that the Pan-Homo last common ancestor was highly similar to Pan troglodytes in ecology and social structure. This is a problematic assumption (Lovejoy, 2009) that in this case potentially mischaracterizes the requirements necessary for a shift to cooking. Studies from a broader perspective have suggested other crucial characters relevant to hominid behavioral evolution (marked unspecialization, neotenyrelated curiosity and information seeking, etc.) that were almost certainly specific to our immediate ancestors (e.g., Lorenz, 1954/1971).

Given these points, and the fact that no other organisms have controlled fire, it is unclear how likely it should be that chimpanzees would understand the process of cooking, even if they do have a suite of capacities that are relevant to an understanding of cooking. Information from chimpanzees, other nonhuman primates, and indeed other nonhuman animals, is vital for helping understand ourselves, but as Rosenblueth and Wiener (1945, p.320) noted, "the best material model for a cat is another, or preferably the same cat." Although we can learn quite a lot about complex behavioral patterns and conceptual knowledge from studying other species, when gauging the advent of uniquely human traits such as the controlled use of fire or the adoption of cooking, the best material model remains, ultimately, Homo erectus and other relevant hominids that first controlled fire and adopted cooking, as is known from the fossil and archeological records.

\section{References}

Ban, S. D., Boesch, C., \& Janmaat, K. R. L. (2014). Taï chimpanzees anticipate high- valued fruit trees from further distances. Animal Cognition, 17, 1353-1364.

Beran, M. J. (2002). Maintenance of self-imposed delay of gratification by four chimpanzees (Pan troglodytes) and an orangutan (Pongo pygmaeus). Journal of General Psychology, 129, 49-66.

Beran, M. J. (2012). Did you ever hear the one about the horse that could count? Frontiers in Comparative Psychology, Article 257.

Beran, M. J., \& Evans, T. A. (2006). Maintenance of delay of gratification by four chimpanzees (Pan troglodytes): The effects of delayed reward visibility, experimenter presence, and extended delay intervals. Behavioral Processes, 73, 315-324.

Beran, M. J., Evans, T. A., Paglieri, F., McIntyre, J. M., Addessi, E., \& Hopkins, W. D. (2014). Chimpanzees (Pan troglodytes) can wait, when they choose to: A study with the hybrid delay task. Animal Cognition, 17, 197-205.

Beran, M. J., Perdue, B. M., Bramlett, J. L., Menzel, C. R., \& Evans, T. A. (2012). Prospective memory in a language-trained chimpanzee (Pan troglodytes). Learning and Motivation, 43, 192-199.

Beran, M. J., Rossettie, M. S., \& Parrish, A. E. (2015). Trading up: Chimpanzees (Pan troglodytes) show self-control through their exchange behavior. Animal Cognition. doi:10.1007/s10071-015-09167

Blaisdell, A. P., Sawa, K., Leising, K. J., \& Waldmann, M. R. (2006). Causal reasoning in rats. Science, 311, 1020-1022.

Boesch, C., \& Boesch, H. (1984). Mental map in wild chimpanzees: An analysis of hammer transports for nut cracking. Primates, 25, 160 170.

Boysen, S. T., \& Berntson, G. G. (1995). Responses to quantity: Perceptual versus cognitive mechanisms in chimpanzees (Pan troglodytes). Journal of Experimental Psychology: Animal Behavior Processes, 21, 82-86.

Bradshaw, J., Healey, L., Thorne, C., MacDonald, D., \& Arden-Clark, C. (2000). Differences in food preferences between individuals and populations of domestic cats Felis silvestris catus. Applied Animal Behaviour Sciences, 68, 257-268.

Brosnan, S. F., Grady, M., Lambeth, S., Schapiro, S., \& Beran, M. J. (2008). Chimpanzee autarky. PLoS ONE, 3, e1518. doi:10.1371/ journal.pone. 0001518

Brosnan, S. F., Jones, O. D., Lambeth, S. P., Mareno, M. C., Richardson, A. S., \& Schapiro, S. J. (2007). Endowment effects in chimpanzees. Current Biology, 17, 1704-1707.

Cachel, S. (2006). Primate and human evolution. New York: Cambridge University Press.

Charnov, E. L. (1976). Optimal foraging: Attack strategy of a mantid. The American Naturalist, 110, 141-151.

Crystal, J. D. (2013). Remembering the past and planning for the future in rats. Behavioural Processes, 93, 39-49.

Darwin, C. (1998). The descent of man, and selection in relation to sex (2nd ed.). Amherst: Prometheus Books (Original work published 1874).

Dashiell, J. (1925). A quantitative demonstration of animal drive. Journal of Comparative Psychology, 5, 205-208.

De Waal, F. B. M. (2001). The ape and the sushi master: Cultural reflections by a primatologist. New York: Basic Books.

Dufour, V., Pele, M., Sterck, E. H. M., \& Thierry, B. (2007). Chimpanzee (Pan troglodytes) anticipation of food return: Coping with waiting time in an exchange task. Journal of Comparative Psychology, 121, $145-155$.

Engels, F. (1953). The part played by labour in the transition from ape to man. Moscow: Foreign Languages Publishing House (Original work published 1876). 
Evans, T. A., \& Beran, M. J. (2007). Chimpanzees use self-distraction to cope with impulsivity. Biology Letters, 3, 599-602.

Evans, T. A., \& Westergaard, G. C. (2006). Self-control and tool use in tufted capuchin monkeys (Cebus apella). Journal of Comparative Psychology, 120, 163-166.

Herzog, N. M., Keefe, E. R., Parker, C. H., \& Hawkes, K. (2015). What's burning got to do with it? Primate foraging opportunities in firemodified landscapes. American Journal of Physical Anthropology. doi:10.1002/ajpa.22885

Herzog, N. M., Parker, C. H., Keefe, E. R., Coxworth, J., Barrett, A., \& Hawkes, K. (2014). Fire and home range expansion: A behavioral response to burning among savanna dwelling vervet monkeys (Chlorocebus aethiops). American Journal of Physical Anthropology, 154, 554-560. doi:10.1002/ajpa.22550

Hirata, S., Watanabe, K., \& Kawai, M. (2001). "Sweet-potato washing" revisited. In T. Matsuzawa (Ed.), Primate origins of human cognition and behavior (pp. 487-508). Tokyo: Springer.

Hopper, L. M., Kurtycz, L. M., Ross, S. R., \& Bonnie, K. E. (2015). Captive chimpanzee foraging in a social setting: A test of problem solving, flexibility, and spatial discounting. PeerJ, 3, e833.

Jaffe, K. E., \& Isbell, L. A. (2009). After the fire: benefits of reduced ground cover for vervet monkeys (Cercopithecus aethiops). American Journal of Primatology, 71, 252-260.

Janmaat, K. R. L., Polansky, L., Ban, S. D., \& Boesch, C. (2014). Wild chimpanzees plan their breakfast time, type, and location. Proceedings of the National Academy of Sciences, 111, 1634316348.

Jolly, C. J. (1970). The seed-eaters: A new model of hominid differentiation on the basis of a baboon analogy. Man, 5, 5-26.

Latimer, B. M., White, T. D., Kimbel, W. H., Johanson, D. C., \& Lovejoy, C. O. (1981). The pygmy chimpanzee is not a living missing link in human evolution. Journal of Human Evolution, 10, 475-488.

Lefebvre, L. (1982). Food exchange strategies in an infant chimpanzee. Journal of Human Evolution, 11, 195-204.

Lefebvre, L., \& Hewitt, T. A. (1986). Food exchange in captive chimpanzees. In D. M. Taub \& F. A. King (Eds.), Current perspectives in primate social dynamics (pp. 476-486). New York: Van Nostrand Reihold.

Lorenz, K. (1971). Psychology and phylogeny. In R. Martin (Ed.), Studies in animal and human behaviour (Vol. 2, pp. 196-245). Cambridge: Harvard University Press (Original work published 1954)

Lovejoy, C. O. (2009). Reexamining human origins in light of Ardipithecus ramidus. Science, 326, 74e1-74e8.

Lovejoy, C. O., Suwa, G., Simpson, S. W., Matternes, J. H., \& White, T. D. (2009). The great divides: Ardipithecus ramidus reveals the postcrania of our last common ancestors with African apes. Science, 326, 100-106.

Mulcahy, N. J., \& Call, J. (2006). Apes save tools for future use. Science, 312, 1038-1040. doi:10.1126/science. 1125456

Osvath, M., \& Osvath, H. (2008). Chimpanzee (Pan troglodytes) and orangutan (Pongo abelii) forethought: Self-control and pre- experience in the face of future tool use. Animal Cognition, 11, 661-674.

Paglieri, F., Focaroli, V., Bramlett, J., Tierno, V., McIntyre, J., Addessi, E., \& Beran, M. J. (2013). The hybrid delay task: Can capuchin monkeys (Cebus apella) sustain a delay after an initial choice to do so? Behavioural Processes, 94, 45-54.

Parrish, A. E., Perdue, B. M., Stromberg, E. E., Bania, A. E., Evans, T. A., \& Beran, M. J. (2014). Delay of gratification by orangutans (Pongo pygmaeus) in the accumulation task. Journal of Comparative Psychology, 128, 209-214.

Raby, C. R., \& Clayton, N. S. (2009). Prospective cognition in animals. Behavioural Processes, 80, 314-324.

Ramirez, I. (1992). Is starch flavor unitary-Evidence from studies of cooked starch. Physiology \& Behavior, 52, 535-540.

Reynolds, B., De Wit, H., \& Richards, J. B. (2002). Delay of gratification and delay discounting in rats. Behavioural Processes, 59, 157-168.

Rosenblueth, A., \& Wiener, N. (1945). The role of models in science. Philosophy of Science, 12, 316-321.

Sanz, C., Call, J., \& Morgan, D. (2009). Design complexity in termitefishing tools of chimpanzees (Pan troglodytes). Biology Letters, 5, 293-296.

Sayers, K., \& Lovejoy, C. O. (2008). The chimpanzee has no clothes: A critical examination of Pan troglodytes in models of human evolution. Current Anthropology, 49, 87-114.

Sayers, K., \& Lovejoy, C. O. (2014). Blood, bulbs, and bunodonts: On evolutionary ecology and the diets of Ardipithecus, Australopithecus, and early Homo. Quarterly Review of Biology, 89, 319-357.

Sayers, K., Raghanti, M. A., \& Lovejoy, C. O. (2012). Human evolution and the chimpanzee referential doctrine. Annual Review of Anthropology, 41, 119-138.

Schoener, T. W. (1971). Theory of feeding strategies. Annual Review of Ecology and Systematics, 2, 369-404.

Shettleworth, S. J. (2010). Clever animals and killjoy explanations in comparative psychology. Trends in Cognitive Sciences, 14, 477481.

Stevens, J. R., Rosati, A. G., Heilbronner, S. R., \& Mühlhoff, N. (2011). Waiting for grapes: Expectancy and delayed gratification in bonobos. International Journal of Comparative Psychology, 24, 99-111.

Suwa, G., Kono, R. T., Simpson, S. W., Asfaw, B., Lovejoy, C. O., \& White, T. D. (2009). Paleobiological implications of the Ardipithecus ramidus dentition. Science, 326, 94-99.

Warneken, F., \& Rosati, A. G. (2015). Cognitive capacities for cooking in chimpanzees. Proceedings of the Royal Society B, 282, 20150229. doi:10.1098/rspb.2015.0229

White, T. D., Asfaw, B., Beyene, Y., Haile-Selassie, Y., Lovejoy, C. O., Suwa, G., \& WoldeGabriel, G. (2009). Ardipithecus ramidus and the paleobiology of early hominids. Science, 326, 75-86.

Wobber, V., Hare, B., \& Wrangham, R. (2008). Great apes prefer cooked food. Journal of Human Evolution, 55, 340-348.

Wrangham, R. W. (2009). Catching fire: How cooking made us human. New York: Basic Books. 